\section{A USABility EVAlUation of MObile Application: A REVIEW ON USABILITY MODEL FOR THE DEAF}

\author{
Shelena Soosay Nathan*, Nor Laily Hashim, Azham Hussain \\ School of Computing, Universiti Utara Malaysia, 06010 UUM, Sintok, \\ Kedah
}

Article history

Received

25 October 2015

Received in revised form

14 December 2015

Accepted

9 February 2016

\section{*Corresponding author sn.shelena@gmail.com}

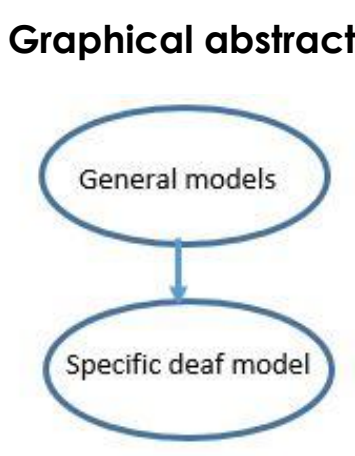

\begin{abstract}
Usability is an important attribute that need more concentration in determining the production of a successful mobile application. Currently mobile applications for the deaf has increased tremendously with the increase of the usage of mobile phones. However, usability evaluation model that best suits the evaluation for mobile application for the deaf is rather very general. Usability of the mobile application for the deaf is very limited that makes the evaluation more challenging and difficult. This study reviews the current usability models provide guidelines and usability dimensions used by researchers and discuss the trend for future evaluation of mobile applications for deaf. Result shows that usability for mobile application for the deaf are limited. This study helps mobile developers and evaluators in evaluating mobile application for the deaf.
\end{abstract}

Keywords: Mobile application, application for deaf, usability model

(c) 2016 Penerbit UTM Press. All rights reserved

\subsection{INTRODUCTION}

According to World Health Organization [1], deafness can be described as lack or complete loss of hearing ability and chances of muteness. People who are having hearing disabilities are known as deaf. Throughout this paper, the term deaf is used to define people suffering from deafness and muteness. Deaf people's main problem is communicating with others [2] [3]. According to [3] also, deaf people are mostly less literate and rarely use English language as a medium of communication.

The deaf community has increased tremendously. In Malaysia itself, deaf people are estimated to be 32000 [2] and this number is increasing every year. According to the Malaysia Welfare Department [4] statistic, as of the year 2014 the total number of disabled people registered under deaf disability is 5499 as shown in Table 1 below.

Statistics show that almost 3 billion mobile phones are connected, actively around the globe and the number keeps increasing from time to time [5]. The usage of mobile phones is not restricted to only normal people, but as well as among disabled people.

Table 1 Total deaf people registered in Malaysia in 2014

\begin{tabular}{cc}
\hline Age Group & Total People Registered \\
\hline Less than 6 years old & 310 \\
$7-12$ years old & 434 \\
$13-18$ years old & 521 \\
$19-21$ years old & 251 \\
$22-35$ years old & 1159 \\
$36-45$ years old & 751 \\
$46-59$ years old & 1101 \\
Above 60 years old & 972 \\
\hline
\end{tabular}

Compatibility of mobile phones for easy communication is being studied continuously to enhance the usability for all groups of people [6]. There are less studies conducted about the deaf children's application. Most of the studies reflect about the mobile application for deaf in general. Besides that, there are even lesser importance given in the studies about the evaluation of the deaf mobile 
applications. Increasing numbers of deaf people show the need to increase more valuable and usable application for this community. Thus, a usability evaluation need to be conducted to ensure the application developed for the deaf community is usable.

Communication is a daunting task for deaf since they are being isolated in the community and confidence level are very low in engaging themselves with normal people. The deaf also tend to leave behind due to their "slow learner" identity. Deaf people are proven to be four times slow leaner than normal people and lacks in capturing a task well [7]. Thus, applications that address to cater this community should take this issue into consideration rather than evaluating mobile applications in general. Therefore the deaf people requirement needs to be identified in generating a better usable application developed for them. Research to evaluate usability for mobile application is very limited and even isolated [6]. Current research in this domain is basically conducted generally to collect subjective data instead of having a proper guideline and model in assisting the evaluation.

Demand for applications are increasing as well as the rate of the rejection, even though applications are developed with great expense and expectations. Reason for the wide rejection of applications is due to the low quality of usability and failure of the application to fulfil user needs. Usability is defined as ease of use and system sustainability for user to carry out tasks easily and efficiently [7]. Ease of use is about user satisfaction while acceptability determine how the product used by the users [8] [9]. Regards to this, the acceptability of a product depends on the full satisfaction of the customer and this can be achieved on improving the ease of use of a product. This is an important and critical issue that need concentration since lacking of guidelines could lead to ineffective interface development for mobile applications [6] [10] [11].

This paper aims to review previous studies on mobile application usability in identifying potential dimensions that could be applied especially for deaf mobile application usability guideline. This is because till to date, there none usability model that have been developed to cater usability evaluation for mobile application for the deaf. Thus, this paper will contribute a comprehensive review of the last decade, studies on usability model in general and specifically for mobile.

\subsection{LITERATURE REVIEW}

Usability depends on user perception about the application development in order to understand the problem and rectify it to produce an effective application. Many mobile applications are being evaluated using the generic guidelines such as [8] and [9]. But there are many things that needed focus in mobile application usability because of the difference between mobile application and desktop application. Many studies have highlighted this issue since the difference between mobile and desktop could possibly only provide partial information on usability. The mobile device is compact in size with a tiny keypad which is touchable. Early research on mobiles focused on small areas such as on design issues and interaction patterns. Currently mobile research has been expanded to wider focus. Some limitations of mobile devices include limited bandwidth, small screen size and small memory capacity and most importantly short life term of mobile battery [6].

Many studies have been conducted by researchers where usability evaluation dimensions evolved over time. Earlier [12] provides metrics for usability by developing usability models align that with ISO [8] standard which comprises of clear usability definition. ISO also strained that usability merely dependent on the user requirement about a product. [13] has elaborated usability as relying on human capability in using with easiness of a product. Proper training and support for the usage of a product has added value for usability. [14] has different definition of usability where they stated usability as human capacity of defining a more efficient and effective user interface to be used. [15] develops a heuristic evaluation to examine usability principles and user interface. [16] on the other hand, defines safety, effectiveness, and efficiency and enjoyable as important aspects to be determined in the usability of a product but it can be varied based on user experience. Later more attributes were added into his concept such as learnability, throughput, flexibility and attitude. Social and emotion is a newly added dimension to determine usability [17]. According to [17] usability is merely on the emotion of the user where relieving anxiety of using computer is one of the requirements for better usability.[18] in his studies declared three main attributes of usability: outcome, process and task. Sub attribute will support proper product usable issue under the three main attribute. Concern on $5 \mathrm{E}$ in usability is adopted by [19] which consists of effectiveness, efficiency, error, ease of use and engagement that needed for an interface. [20] also finds usability as a tool for users to decide on the quality of the system that make it usable and error tolerance. By ensuring this, [20] believes the usability goal will be achieved. In another study by [21] he believes when user interface can accept ten attributes easily thus usability goal will be achieved without a doubt. Ten attributes in his study comprise of effectiveness, efficiency, predictability, satisfaction, correlation, learnability, safety, trustfulness, accuracy, universality and usefulness.

Though many studies discuss on usability in general, few attempts have been made by researchers to study on mobile usability. For example, [22] develop a framework in his research by implementing eight requirements in developing models which eventually has the dimension of effectiveness, usefulness, 
efficiency, consistency, compatibility as well as understand ability. [23] believes that usability for mobile must consider problem on a product and human error, thus he identifies a few dimension for usability for mobile using a hybrid technique which are learnability, satisfaction, intuitive, useful, error and understandable. While [24] identifies learnability, functionality, easy manual, useful, usable, satisfaction, atheistic, and simplicity as usability dimensions for mobile cancer system.

There a number of usability that have been studied about usability dimension in general and mobile in specific. Each of the studies differs in these dimension for usability measurement in relating to the environment and product to be evaluated. Findings from previous studies identify that there is a no usability model being studied in for the use of designing mobile application for special need community and in the case of this paper deaf person. Though there are many applications being developed to help this community yet a proper usability model to guide usable product development is needed. This is to ensure the development is done according to user requirement and the context of content to be delivered easily for special need people.

Challenging issue for deaf mobile application is to make them usable and accessible [25]. Based on a review of the deaf requirement for technology, some features should be considered important when it is intended for the deaf. Some of the main requirements identified to fit into the mobile applications for the deaf are [26]:

Vibrating and visual alerts: alert sound is replaced with vibration or visual alert.

Messaging: features in messaging for the deaf should offer a different alternative rather than focusing only on text, video and multimedia service should be added.

Multimedia: image or video features allow better usage of mobile by the deaf since they rely on sign language most of the time and have low literacy level.

Video conferencing: this helps deaf people to communicate with others easily through video on a real time basis.

Captioning: provide captions for video or movie provide to better use of mobile among deaf.

Thus, the normal guideline of accessibility for the disable cannot be applied directly for applications meant for deaf users [26]. This is due to some criteria that the deaf people behave and react differently from other disabilities. Thus, guideline, especially for the deaf was developed by [27] from existing accessibility guidelines. The main requirement for mobile application as listed above was given extra care in developing this guideline. The proposed guideline consists of 20 dimensions as listed below:

$\square$ Accurate reproduction of text and sign language

Output is under control and not restricted

Simple language with visual display

$\square$ Visibility of system status

\author{
Match real life and system \\ ] User control \\ Call recognition \\ Atheistic \\ Anticipation \\ Consistency \\ $\checkmark$ Efficiency \\ $\square$ Explore able interface \\ $\checkmark$ Human interface control \\ Latency reduction \\ Readability \\ Learnability \\ $\checkmark$ Navigation \\ ] Usability \\ Accessibility \\ $\square$ Usefulness
}

The above listed guideline have indicate some important aspect and content that is important for the deaf and mobile application developed for them. This will ensure accessibility and integration of mobile usage among deaf more comfortable and engaging. since deaf are a slow learner and mostly isolated in the community, they are very self-focused and these guidelines would help them to interact with others more confidence. Yet, guideline above will help developer and still lacking of usability model used for the development of deaf mobile applications. Lacking of studies about the usability model for deaf mobile application has limited the portraying of depth literature review on deaf especially.

\subsection{USABILITY MODELS}

Usability models are conceptual view about the area to be focused and metrics that should be tested. These will help in the usability evaluation to be conducted on an application. Usability evaluation is about planning a task determining a method for evaluation and deciding the nature of data and rules in collecting it [8] [28]. Thus, in measuring the interface usability plays a vital role to determine the effectiveness, accurateness and efficiency of an application to give a usage satisfactory to user as many usability model agrees. Table 2 shows the usability model available in general and was adopted by many researchers from year 1991 till to date 2015 and the dimensions that were used. While Table 3 listed usability model for mobile application.

\subsection{DISCUSSION AND CONCLUSION}

It is important that deficiency of studies in the deaf mobile application area should be advanced in the future. This is not only to fulfil the need of an academician, but also for the deaf community beneficial. Since they are being isolated from the community and difference between them from the normal hearing people the deaf people tend to have 
lack of self-esteem and they prefer to move out from the community.

Table 2 Usability models in general

\begin{tabular}{|c|c|}
\hline $\begin{array}{l}\text { Usability } \\
\text { Models }\end{array}$ & Dimensions \\
\hline $\begin{array}{c}\text { Shackel } \\
\text { Model (1991) }\end{array}$ & $\begin{array}{l}\text { Effectiveness } \\
\text { Learnability } \\
\text { Flexibility } \\
\text { Attitude }\end{array}$ \\
\hline $\begin{array}{c}\text { Nielsen } \\
\text { Model (1993) }\end{array}$ & $\begin{array}{l}\text { Learnability } \\
\text { Efficiency } \\
\text { Memorability } \\
\text { Error } \\
\text { Satisfaction } \\
\end{array}$ \\
\hline ISO (1998) & $\begin{array}{l}\text { Effectiveness } \\
\text { Efficiency } \\
\text { Satisfaction } \\
\end{array}$ \\
\hline ISO (2001) & $\begin{array}{l}\text { Understandability } \\
\text { Operability } \\
\text { Learnability } \\
\text { Attractiveness } \\
\text { Usability } \\
\text { Compliance }\end{array}$ \\
\hline $\begin{array}{l}\text { Preece et. } \\
\text { al (1993) }\end{array}$ & $\begin{array}{c}\text { Safety } \\
\text { Effectiveness } \\
\text { Efficiency } \\
\text { Enjoyableness } \\
\end{array}$ \\
\hline \multirow[t]{3}{*}{$\begin{array}{l}\text { Chrusch } \\
(2000)\end{array}$} & $\begin{array}{cc}\text { Outcome } & \text { Efficiency } \\
& \text { Effectiveness } \\
& \text { Satisfaction } \\
\end{array}$ \\
\hline & $\begin{array}{l}\text { Ease of use } \\
\text { Interface } \\
\text { Learnability } \\
\text { Memorability } \\
\text { Error recovery }\end{array}$ \\
\hline & $\begin{array}{l}\text { Functionality } \\
\text { Compatibility }\end{array}$ \\
\hline $\begin{array}{r}\text { Dee and } \\
\text { Allen (2001) }\end{array}$ & $\begin{array}{l}\text { Efficiency } \\
\text { Effectiveness } \\
\text { Production } \\
\text { Satisfaction } \\
\text { Trustfulness } \\
\text { Accuracy }\end{array}$ \\
\hline
\end{tabular}

Thus, in accordance with the advancement of technology, mobile application, especially for deaf need more consideration in the development. Difference between mobile and desktop application should be realized and a suitable usability model should be developed for specific evaluation instead of generalizing it since each user and his or her task differs from one another. The key point of usability is to make product usable, thus it must be usable even for the deaf people. None of the mobile user should be isolated since their requirement unable to be fulfilled. According to the above discussion, usability dimension of mobility is very limited and even isolated in case for deaf users. Each of these usability dimensions of the available model are influenced by user, device and task to be fulfilled. Developer have to understand this feature to determine the usability dimension to be considered for deaf mobile application. This paper aims to review on existing usability models in general for desktop and mobile applications, In the future, this study will be extended to study on guidelines for deaf mobile application and important features to be considered in development. The paper will be beneficial for usability evaluators in the field of Human Computer Interaction.

\section{Acknowledgement}

We are grateful for the UUM for the opportunity and motivation given in conducting this study.

\section{References}

[1] World Health Organization. Retrieved on 2/5/2015 from: www.who.in.

[2] Mohid, S. Z., and N. A. M., Zin. 2010. Courseware accessibility for deaf. In Information Technology (ITSim), 2010 International Symposium. 1: 1-5

[3] Ng'ethe, G. G., E. H., Blake, and M., Glaser. 2014. Mobile Aid for Deaf people learning Computer Literacy Skills. Journal of Deaf Studies and Deaf Education. 1: 1-2

[4] Jabatan Kebajikan Masyarakat Malaysia. 2014. Retrieved on 5/5/2015 from www.jkm.gov.my.

[5] International Telecommunication Union, 2014. Retrieved on 3/4/2015 from: www.itu.int/en/ITU-D/Statistics/Pages

[6] Hussain, A. 2012. Metric Based Evaluation Of Mobile Devices: Mobile Goal Question Metric (mGQM) (Doctoral dissertation, University of Salford).

[7] Marschark, M., and M., Harris. 1996. Success And Failure In Learning To Read: The Special Case Of Deaf Children. Reading comprehension difficulties: Processes and intervention, 279-300.

[8] ISO 9126. 1991. Software Product Evaluations- Quality characteristics and guidelines for their use, ISO DIS 9126.

[9] Nielsen, J. (1994). Usability engineering. Elsevier.

[10] Chittaro, L. 2006. Visualizing Information On Mobile Devices. Computer. 39 (3): 40-45.

[11] Hussain, A., \& Kutar, M. 2012. Usability Evaluation of SatNav Application on Mobile Phone Using mGQM. International Journal of Computer Information Systems and Industrial Management Applications. 4(2012): 92-100.

[12] Holcomb, R., \& A. L., Tharp. 1991. Users, a software usability model and product evaluation. Interacting with Computers. 3(2): 155-166.

[13] Shackel, B. 1991. Usability-Context, Framework, Definition, Design And Evaluation. Human Factors For Informatics Usability. 21-37.

[14] Hix, D., and Hartson, H. R. 1993. Developing User Interfaces: Ensuring Usability Through Product \& Process. John Wiley \& Sons, Inc.

[15] Nielsen, J. 1993. Usability Engineering. Academic Press. New York.

[16] Preece, J., and D., Benyon. 1993. A Guide To Usability: Human Factors In Computing. Addison-Wesley Longman Publishing Co., Inc.

[17] Logan, R. J. 1994. Behavioral and emotional usability: Thomson consumer electronics. In Usability in practice. 5982

[18] Chrusch, M. 2000. The whiteboard: seven great myths of usability. Interactions. 7(5): 13-16.

[19] Quesenbery, W. 2003. The Five Dimensions Of Usability. Content And Complexity: Information Design In Technical Communication. 81-102.

[20] Campbell, K., And R., Aucoin. 2003. Value-Based Design Of Learning Portals As New Academic Spaces. Designing Portals: Opportunities And Challenges. 162-185. 
[21] Dee, C., and M., Allen. 2006. A Survey Of The Usability Of Digital Reference services on academic health science library web sites. The Journal of Academic Librarianship. 32(1): 69-78

[22] Heo, J., D. H., Ham, S., Park, C., Song, and W. C., Yoon, 2009. A Framework For Evaluating The Usability Of Mobile Phones Based On Multi-Level, Hierarchical Model Of Usability Factors. Interacting with Computers. 21 (4): 263-275.

[23] Biel, B., T., Grill, and V., Gruhn. 2010. Exploring The Benefits Of The Combination Of A Software Architecture Analysis And A Usability Evaluation Of A Mobile Application. Journal of Systems and Software, 83(11): 2031-2044.

[24] Holzinger, A., P., Kosec, G., Schwantzer, M., Debevc, R., Hofmann-Wellenhof, and J., Frühauf. 2011. Design And Development Of A Mobile Computer Application To Reengineer Workflows In The Hospital And The
Methodology To Evaluate Its Effectiveness. Journal of biomedical informatics. 44(6): 968-977.

[25] Shneiderman, B. 2000. Creating Creativity: User Interfaces For Supporting Innovation. ACM Transactions on Computer-Human Interaction (TOCHI). 7(1): 114-138.

[26] Mazlina, A. M., K. M., Ananthi, and T., Herawan. 2012. A Design of Educational Multimedia Software for Disability: A Case Study for Deaf People. In the International Conference on Modeling and Simulation 2012 (MAS 2012). Jeju, Korea. 28-30 November 2012. 1-8.

[27] Yeratziotis, G., \& van Greunen, D. (2013, May). Making ICT accessible for the deaf. In IST-Africa Conference and Exhibition (IST-Africa). 1-9

[28] ISO 924-11 1998. Guidance On Usability- International Standard: ISO 9241-11.

[29] ISO/IEC 9126-1, 2001. Software Engineering- Product Quality-Part 1: Quality Model. 